\title{
Alzheimer's Disease: An Epidemiologic Disaster From Nutritional Perspective
}

\author{
Magda Antal ${ }^{1}$, Szabolcs Péter $^{2 *}$, Manfred Eggersdorfer ${ }^{2,3}$ \\ ${ }^{1}$ Pannónia Street 66, Budapest 1133, Hungary \\ ${ }^{2}$ DSM Nutritional Products Ltd., Wurmisweg 576, Kaiseraugst 4303, Switzerland \\ ${ }^{3}$ University Medical Center Groningen, University of Groningen, Hanzeplein 1, The Netherlands
}

Received: November 20, 2016; Accepted: December 15, 2016; Published: January 25, 2017

*Corresponding author: Szabolcs Péter MD, PhD, Principal Scientist, DSM Nutritional Products Ltd., P.O. Box 2676, 4002 Basel, Switzerland, Tel.: +41 61815 8966; Fax: +41 61815 8540; E-mail: szabolcs.peter@dsm.com

\begin{abstract}
Alzheimer disease (AD) is a progressive, multifactorial, untreatable neurodegenerative disease with worldwide increasing incidence and prevalence in the ageing societies. Besides pharmaceutical drug development there is also a need for alternative solutions for both prevention and treatment. The major objective of this article is to summarize the non-modifiable and some modifiable risk factors of $\mathrm{AD}$, including nutrition and diet, and to discuss different aspects of $\mathrm{AD}$ prevention. Optimizing the nutritional status of the general population as a preventive measure may provide additional support to therapeutic concepts as they become available. Already several randomized controlled trials demonstrated promising results for certain nutrients to decrease the risk of developing $\mathrm{AD}$ and maintaining cognitive performance. Moreover, symptoms of AD such as neuroinflammation, glucose dysregulation, homocysteine accumulation and neuronal loss can be considerably influenced by nutrition. Thus, lifelong optimal supply of essential micro- and macronutrients may contribute to delay the onset of AD. However, currently the scientific evidence regarding the effects of nutrients on $\mathrm{AD}$ is incomplete and there are many opportunities for nutrition scientists to contribute to the clarification of the conflicting results and adjust guidelines accordingly.
\end{abstract}

Keywords: Alzheimer`s Disease; Public Health; Nutrition; Vitamins; Polyunsaturated Fatty Acids.

\section{Introduction}

In 2015, globally the average Life Expectancy (LE) at birth was 71.4 years, while the healthy life expectancy at birth was 63.1 years [1]. However, there are great differences in LE among countries and between genders: For example in the US men live 76.9 years on average, while women live 81.6 years; these data in the UK are 79.4 and 83.0 years, respectively; while Japan has one of the highest LE in the world for men (80.5 years) and for women (86.8 years) as well [2].

The share of population aged 65 and over is increasing in every EU member state: In 2014 the 65-79 years age group represented $13.4 \%$ of the population, while the rate of people aged 80 years and over was $5.1 \%$. The estimated ratio of these two age groups in the $28 \mathrm{EU}$ countries for 2040 is $17.9 \%$ and $9.9 \%$, and for 2050 it is projected to be $17.2 \%$ and $10.9 \%$, respectively [3] (Figure 1).

Based on the data available, LE during the $20^{\text {th }}$ century increased by more than 30 years. By the year 2040 more than a quarter of the Europeans will be older than 65 years and one in seven will be at least 75 years of age. More importantly, health expectancy on average is 8-11 years shorter than LE and loss of cognitive functions and increase in dementia are major contributors of disability and disease during these last couple years of life $[4,5]$.

Alzheimer's Disease (AD) is the most common cause of dementia in people aged 60 years or older, representing approximately $60-70 \%$ of all cases [6].

Currently at least 35 million peopleare affected by $\mathrm{AD}$ worldwide and this number is expected to quadruple by the year 2050. Although mortality due to HIV, stroke and heart disease decreased between 2000 and 2013 by 52\%, 23\% and 14\%, respectively, death cases related to $\mathrm{AD}$ increased by $71 \%$ within the same timeframe, making AD the fourth leading cause of death in developed countries [7].

The prevalence of AD increases with age, for example the proportion of people with AD in the US in 2015 was estimated as follows: <65 years: $4 \%$; $65-74$ years: $15 \%$; $75-84$ years: $43 \%$; 85+ years: $38 \%$ [7].

\section{Definition of AD}

Alois Alzheimer identified the first case of AD in a 51 year old woman, whose brain autopsy showed plaques and tangles that characterize AD [8].

$\mathrm{AD}$ is a degenerative brain disease of unknown origin, usually developing slowly during the late middle age or in old age and worsens with time. AD results in progressive memory loss, impaired thinking, disorientation, changes in personality and mood. These symptoms are leading to profound decline in 


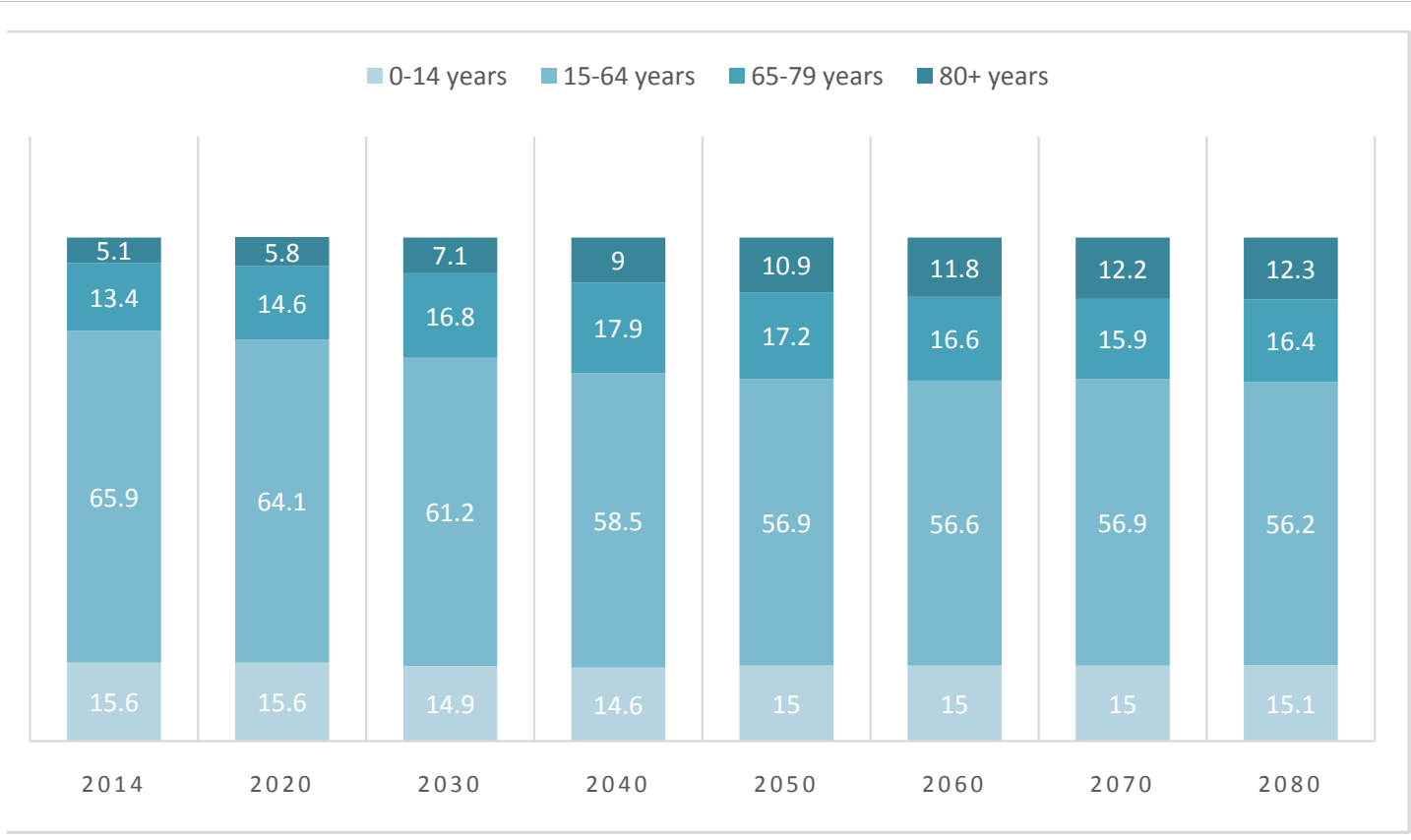

Figure 1: Population structure by major age groups, EU-28, 2014-80 (\% of total population) [3]

cognitive and physical functioning, which is histopathologically characterized by degeneration of brain neurons, especially in the central cortex, and by the presence of neurofibrillary tangles and plaques containing $\beta$ amyloid $[7,9,10]$ (Table 1).

\section{Risk factors and protective circumstances}

Given the presence of numerous interconnected genetic and environmental factors, AD is unquestionably considered as a complex multifactorial disease. However, its cause or causes are not known. Risk factors are grouped into two categories: Those that cannot be altered and others that are possible to modify [11].

\section{Non modifiable risk factors}

Age: $\mathrm{AD}$ is not part of the normal ageing process, but age is the strongest independent risk factor for the development of $\mathrm{AD}$. This does not mean that most people develop AD as they age, and in fact most do not. However, some younger people still in their 40 s and 50 s can be diagnosed with the early onset form of the disease. Over the age of 65 years the risk of developing $\mathrm{AD}$ doubles ca. every five years. In the US for example the incidence of $\mathrm{AD}$ within the age group of $65-74$ years is 2 per 1,000 people, in the age group of 75-84 years it is 13 and in the $>85$ years group 39 per 1,000 people. According to the Framingham study, the estimated lifetime risk for $\mathrm{AD}$ is $9.1 \%$ for men and $17.2 \%$ for women at age of 65 years; $10.2 \%$ and $18.5 \%$ at 75 years; $12.1 \%$ and $20.3 \%$ at 85 years, respectively [7].

Gender: Age related loss of sex steroid hormones is an established risk factor for the development of AD in both men and women. Estrogens and androgens exert general neuroprotective propertiess, including protection from neuronal death, increase spine density, facilitate synaptic plasticity and improve certain aspects of cognition. In addition, estrogens and androgens regulate key processes implicated in $\mathrm{AD}$ pathogenesis. Due to the loss of estrogen and progesterone, $\beta$ amyloid protein $(A \beta)$ accumulation and tau phosphorylation are increasing.

Evidence suggests that $\mathrm{AD}$ pathogenesis is regulated by estrogen and progesterone in females, but primarily by androgens in males $[12,13]$.

Menopause: It is known that $\mathrm{AD}$ is more prevalent in women, than in men. The higher prevalence of $\mathrm{AD}$ in women can be partly explained by the differences in life expectancy, however according to several studies, the incidence of AD is also higher in women. Moreover, AD pathology and AD-related cognitive decline are more marked in women than in men. This can be partly justified by the relatively abrupt loss of oestrogen and progesterone in women and the more gradual decrease of testosterone level in men. The 17 beta-estradiol concentration in the female brain decreases sharply at menopause, but with very little additional decrease with ageing afterwards. Moreover, there is a stronger association with apolipoprotein E\&4 Allele (APOE\&4) in $\mathrm{AD}$ in women than in men, and this association correlates with greater hippocampal atrophy in women. The underlying cause for increased vulnerability of females to AD-like pathology is ambiguous.

Hormone Replacement Therapy (HRT) in menopausal women seems to offer promising results in reducing the risk of AD. Controversally, according to a prospective study, HRT may even increase the risk of dementia. Recent clinical data suggest that AD risk is reduced when HRT is initiated in midlife, but is exacerbated by HRT administration in late life $[12,13]$. 


\begin{tabular}{|c|c|c|}
\hline $\begin{array}{l}\text { Mild Alzheimer's disease (early-stage) lasts } \\
\text { for 2-4 years }\end{array}$ & $\begin{array}{l}\text { Moderate Alzheimer's disease (middle-stage) } \\
\text { lasts for 2-10 years }\end{array}$ & $\begin{array}{l}\text { Severe Alzheimer's disease (late stage) lasts } \\
\text { for } 1-3+\text { years }\end{array}$ \\
\hline $\begin{array}{l}\text { In the early stages of } \mathrm{AD} \text { the patient may function } \\
\text { independently }\end{array}$ & $\begin{array}{l}\text { As the disease progresses, the patient will require } \\
\text { a greater level of care }\end{array}$ & $\begin{array}{l}\text { As memory and cognitive skills continue to } \\
\text { worsen, personality changes may occur and } \\
\text { patients need extensive help with daily activities }\end{array}$ \\
\hline $\begin{array}{l}\text { - Difficulty by performing tasks in social or work } \\
\text { settings } \\
\text { - Forgetting text that one has just read } \\
\text { - Losing or misplacing objects } \\
\text { - Increasing problems with planning or organizing }\end{array}$ & $\begin{array}{l}\text { - Forgetting events or own personal history } \\
\text { - Feeling unpredictable or withdrawn in socially } \\
\text { or mentally challenging situations } \\
\text { - Unable to recall own address or phone number } \\
\text { - Confusion about present time and location } \\
\text { - Need for help choosing proper clothing for the } \\
\text { season or occasion } \\
\text { - Trouble controlling bladder and bowels } \\
\text { - Changes in sleep patterns (e.g. sleeping during } \\
\text { the day and becoming restless at night) } \\
\text { - Increased risk of wandering and becoming lost } \\
\text { - Personality and behavioral changes (incl. } \\
\text { suspiciousness and delusions, compulsive, } \\
\text { repetitive behaviour etc.) }\end{array}$ & $\begin{array}{l}\text { - Full-time assistance needed with daily personal } \\
\text { care } \\
\text { - Lose awareness of recent experiences and } \\
\text { surroundings } \\
\text { - High levels of assistance required with daily } \\
\text { activities and personal care } \\
\text { - Experience changes in physical abilities (incl. } \\
\text { the ability to walk, sit, swallow) } \\
\text { - Increasing difficulty communicating } \\
\text { - Vulnerable to infections, esp. pneumonia }\end{array}$ \\
\hline
\end{tabular}

Genetics: AD can be categorized into two subtypes: Early onset $\mathrm{AD}(\mathrm{EOAD})$ or familial $\mathrm{AD}(\mathrm{FAD})$ and late onset $\mathrm{AD}$ (LOAD) [14].

\section{Familial AD}

FAD is expressed as a Mendelian trait with dominant inheritance, and around $2-5 \%$ of all $\mathrm{AD}$ cases belong to this category. If a person has FAD, each of their children have $50 \%$ chance of inheriting the disease; when both partents have FAD, their children will develop AD in adulthood. FAD cases occur in people between the age of 30-60 years. Characteristic pathological features in the brain include progressive accumulation of $A \beta$ in the form of senile plaques outside the neurons, and twisted strands of protein (neurofibrillary tangles, hyperphosphorilated tau protein) inside the neurons. These changes are eventually accompanied by low-grade chronic inflammation and oxidative stress, causing neuron damage and cerebral cortical atrophy, which in the long run leads to dementia $[14,15]$.

a. Amyloid Cascade Hypothesis (ACH): According to the $\mathrm{ACH}$, the deposition of $\mathrm{A} \beta$ is the initial event in $\mathrm{AD}$, leading to the formation of extracellular senile plaques and then to neurofibrillary tangles, neural cell death and ultimately clinical dementia [16].

Specially three mutations in the genes of the Amyloid Precursor Protein (APP), Presenilin1 (PSEN1) and Presenilin2 (PSEN2) result in the alteration of $A \beta$, and cells produce $A \beta$ peptides of variable length: A peptide of 40 amino acids $(A \beta 40)$ is the most prevalent, whereas the longer $A \beta 42$ isomer appears to be the key pathogenic form for FAD. During physiological circumstances, APP is cleared by $\alpha$-secretase, producing a dissolved form (amyloid $\alpha$ ) which is released into the extracellular compartment $[17,18]$.

Neuronal microtubules transports nutrients, molecules and information to other cells. Tau protein plays a key role in keeping the microtubule system stable. In AD the threads of tau become tangled and twisted, thus the microtubule become instable and disintegrated, collapsing the entire neuronal transport system. Plaques and highly Phosphorylated Neurofibrillary Tangles (NFT) lead to functional failure of synapses, synaptic loss and finally neural death [19].

However, the current hypothesis of amyloid cascade and tau pathology only partially explains the pathophysiology of $\mathrm{AD}$, which is considered to have a multifactorial etiology. Musiek and Holtman argued that $A \beta$ acts primarily as a trigger of other downstream processes, particularly tau aggregation, which mediate neurodegeneration: Thus $A \beta$ appears to be necessary, but not sufficient to cause AD by itself. At the same time Herrup also rejects the $\mathrm{ACH}$ and suggests that amyloid is not even necessary for AD development. Most probably a "multiple reason" hypothesis will be able to account for all the various aspects that underline the disease process, and to differentiate between normal and pathological brain ageing [20,21].

A comprehensive review by Morris et al. summarized the pros and cons of the amyloid cascade hypothesis. They concluded that $\mathrm{A} \beta$ in the $\mathrm{AD}$ brain is a consequence rather than the primary 
cause of the disease. Since the amyloid hypothesis is still incomplete and also highly debated, it is worthwhile to consider other alternative theories [22].

b. $\mathbf{A} \boldsymbol{\beta}$ Clearance Systems: It has been hypothesized that $A \beta$ accumulation results from an imbalance between $A \beta$ production and clearance. $A \beta$ clearance seems to be impaired in both early and late forms of AD. Recently, the clearance systems of the brain were described in relation with AD pathology, and with a special focus on $A \beta$ : the blood-brain barrier clearance, the intra- and extracellular degradation clearance, the interstitial fluid bulk flow clearance and the cerebrospinal fluid adsorption clearance. The precise understanding of the mechanisms of clearance dysfunction in $\mathrm{AD}$ is essential for developing strategies to reduce excess deposition of neurotoxic proteins and to stop the related pathological changes. It still remains a question whether the observed clearance defect in $\mathrm{AD}$ is a cause or a consequence of the pathology or merely a coincidence. Further examination of the $\mathrm{A} \beta$ clearance defect might provide a useful biomarker for the reversible clinical pathology of $\mathrm{AD}$ [23].

\section{Late Onset AD (LOAD)}

LOAD usually develops in patients older than 60 years of age. The causes are not completely understood yet, but genetic, environmental and lifestyle factors may contribute to the progression and severity of this form of the disease. Nevertheless, based on clinical evaluation of a community population sample, the prevalence is strongly associated with age: $3 \%$ between 65 74 years; $18,7 \%$ between $75-84$ years; and $47,2 \%$ over 85 years [24].

Apolipoprotein E (APOE) is a major determinant of the fat soluble vitamin transport in blood to the peripheral tissues, as well as in the central nervous system to neurons via APOE receptors. APOE is polymorphic with three major alleles: $\varepsilon 2$, $\varepsilon 3$, and $\varepsilon 4$. The APOE $\varepsilon 2$ form is carried by $8 \%, \varepsilon 3$ about $77 \%$ and $\varepsilon 4$ around $15 \%$ of the population, respectively. It has been proposed that APOE $\varepsilon 2$ may provide some protection against $\mathrm{AD}$, while APOE $\varepsilon 3$, the most frequent allele is believed to play a neutral role in the disease, although both APOE $\varepsilon 2$ and $\varepsilon 3$ may enhance the clearance of $A \beta$. There are data showing that APOE 2 reduces the risk of dementia in persons older than 90 years. APOE 4 probably increases the risk of AD by initiating and accelerating $A \beta$ accumulation in the brain. This allele is present in $40 \%$ of patients with $\mathrm{LOAD}$, and it is considered to be the major genetic risk factor of AD. However, inheriting an APOE $\varepsilon 4$ allele does not necessarily mean a definitive development of $\mathrm{AD}$, but the risk of LOAD is ca. 8-10 times higher in homozygous individuals as compared to the risk in heterozygous persons [18, 25-27]. Furthermore it has been demonstrated that APOE\&4 accelerates age dependant cognitive decline and worsens memory performance and functional activities as well as hippocampal atrophy $[26,28]$.

Epidemiological, in vitro and animal studies suggested that APOE\&4 causes neuronal disturbances and behavioural deficits in vivo via multiple ways, either independently or in combination with other factors, such as $\mathrm{A} \beta$ and tau. APOE 44 contributes to the impairment of the oxidative defence system, dysregulation of neuronal signalling pathways, increased phosphorylation of tau and formation of neurofibrillary tangles. [26, 27, 29].

\section{Modifiable risk factors, life-course concept}

This theory aims to understand how risk factors and protective circumstances interact during gestation, childhood, adolescence, and adult life to influence the development of later disease [30].

Intrauterine life is important for the maturation and development of the brain and the nervous system . Inturn, brain development may influence the risk of cognitive impairment and dementia in older age.

The brain reaches $95 \%$ of its final size at age 6 , the maximal brain size and skull circumference are reached between 11 and 15 years. Thereafter brain size decreases, while skull circumference remains constant. Thus the circumference of the adult skull reflects the brain size at its peak [30]. The individual capacity to withstand pathological alterations is usually referred to as Brain Reserve (BR) or Cognitive Reserve (CR) [31].

$\mathrm{BR}$ refers to qualitative measures, such as brain size, number of neurons and synapses. BR is a passive protection against the consequences of brain damage, mediated by larger brain or more neurons and synaptic connections [31]. Epidemiological and clinical studies have consistently shown that at similar levels of $\mathrm{AD}$ pathology, higher estimates of $\mathrm{BR}$ and greater Intracranial Volume (ICV) were related to less severe symptoms. Perneczky et al. involved in the Mirage study suggested that larger head circumference is associated with less cognitive impairment. The larger brains contain more neurons, synaptic connections and bigger brain size is mostly determined in early childhood. The results suggest that optimal neural development in the first couple of years provides a buffer against cerebral pathology in late life [31]. Although greater premorbid brain size seems to protect against clinical deterioration in AD related brain atrophy in Mild Cognitive Impairment (MCI), the protective effects of morphologic reserve seem to be limited to early clinical AD [32].

$\mathrm{CR}$ is characterized by active processes through alternative neural pathways, helping to compensate the effect of brain pathology in its clinical presentation. CR includes compensatory strategies like education, Intelligence Quotient (IQ), literacy and the integrity of social networks. Epidemiological data suggest that persons with higher education, occupational competence and participation in leisure activities have a lower risk for developing $\mathrm{AD}$ [33]. It is widely accepted that $\mathrm{CR}$ is an important protective factor against $\mathrm{AD}$, but the question remains how to maximize $\mathrm{CR}$ of individuals. In this regard several suggestions have been proposed by Stern, such as the extension of the person`s social network, early life education and cognitive activities in later life [34].

\section{Nutrition}

There is an increasing interest to clarify the role of nutrition in AD. This review is focusing on certain key nutritional compounds and a few diseases/disorders that may be connected to AD. It also takes these factors into account concerning the development and 
progression of $\mathrm{AD}$, and their role in prevention. As $\mathrm{AD}$ is currently incurable, these factors need to be very carefully investigated.

I. Vitamin E: Significant positive association was found for the beneficial effect of vitamin $\mathrm{E}$ and the prevention of AD: Grade I. evidence indicates that vitamin E may decrease the risk for the development of AD [35].

Vitamin $\mathrm{E}$ is a fat soluble vitamin with eight isoforms: $\alpha$-, $\beta-, \gamma-, \delta$-tocopherol and $\alpha-, \beta-, \gamma-, \delta$-tocotrienol. All forms have a chromanol ring with a hydroxyl group that can serve hydrogen atom to reduce free radicals, and a hydrophobic side chain which allows its penetration into biological membranes. The human body preferentially uses $\alpha$-tocopherol; this form is found in the largest quantities in the blood and the tissues [36].

\section{a. Function of $\alpha$-tocopherol:}

1.) Antioxidant activity: Alpha-tocopherol is a chain breaking antioxidant preventing the propagation of Reactive Oxygen Species (ROS) in membranes and in plasma lipoprotein. When a molecule of $\alpha$-tocopherol neutralizes ROS, it oxidizes to a less active tocopherol radical, which is reduced by a hydrogen donor such as vitamin C. In this way the chain reaction of lipid peroxidation is broken [36].

It has been suggested that vitamin E may prevent hyperphosphorylated tau protein dysfunction. Additionally, vitamin $\mathrm{E}$ has been related to reduced rate of neuronal death induced by $A \beta$ protein in cultures of hippocampal and cortical cells [37].

2.) Anti-inflammatory activity: Recent studies indicate that $\gamma$ - and $\delta$-tocopherols and $\gamma$-tocotrienol have unique anti-inflammatory properties that are superior to those of $\alpha$-tocopherol in prevention and therapy against chronic diseases. These vitamin $\mathrm{E}$ forms scavenge reactive nitrogen species, inhibit cyclooxygenase- and 5-lipoxygenase-catalysed eicosanoids and suppresses pro-inflammatory signalling. Animal and human studies show that $\gamma$-tocopherol and tocotrienols may be useful against inflammation associated diseases [38].

3.) Enzymatic activity regulator: Protein Kinase C (PKC) plays a role in smooth muscle growth and can be inhibited by $\alpha$-tocopherol: $\alpha$-tocopherol has a stimulatory effect on protein phosphatase $2 \mathrm{~A}$, which in turn cleaves phosphate groups from $\mathrm{PKC}$, leading to its deactivation, bringing the smooth muscle growth to a halt $[39,40]$.

4.) Protective role of vitamin E during oxidative stress: Oxidative stress is a risk factor for AD. In healthy individuals the generation of ROS should be in balance with antioxidant defences.

Growing evidence suggests that vitamin E has a neuroprotective effect by inhibiting oxidative stress and scavenging $A \beta$-associated free radicals [41]. b. Clinical trials concerning vitamin E supplementation: Compared to cognitively normal subjects, AD and MCI patients have lower blood concentrations of total tocopherols, total tocotrienol and total vitamin E [41].

According to the Cochrane database, only three studies met the inclusion criteria to investigate the effect of vitamin $\mathrm{E}$ in the treatment of MCI or AD [42].

Sano et al. investigated the effect of selective monoamine oxidase inhibitor selegiline (10 mg/d), $\alpha$-tocopherol (2,000 IU/d) or both and placebo for two years. In patients with moderately severe impairment form of $\mathrm{AD}$, treatment with selegilene, $\alpha$-tocopherol or their combination slowed the progression of the disease [43].

Lloret et al. treated patients with 800 IU vitamin E/d or placebo for six months. Blood oxidized glutathione (GSSG) was measured and cognitive tests were analyzed. Patients were divided in two groups: In the "respondents" to vitamin E, GSSG levels were lower after treatment and scores of cognitive tests were unchanged. In the "non-respondent" group, vitamin E was not effective in preventing oxidative stress, and cognition decreased sharply. Authors suggested that vitamin E supplementation in AD patients cannot be recommended without the determination of its antioxidant effect in each patient [44].

Petersen et al. administered 2,000 IU vitamin E daily, $10 \mathrm{mg}$ of donepezil daily or placebo to patients with amnestic subtype of MCI for three years. They concluded that vitamin E had no benefit for patients with MCI [45].

According to the conclusion of the Cochrane group, there is no convincing evidence that vitamin $\mathrm{E}$ is beneficial for the treatment of $\mathrm{AD}$ and $\mathrm{MCI}$, and future trials assessing vitamin E treatment in AD should not be restricted to $\alpha$-tocopherol [42].

One of the largest and longest treatment trials, involving patients with mild to moderate $\mathrm{AD}$, studied the effect of $\alpha$-tocopherol (2,000 IU/day) or memantine (20 mg/d) alone or in combination, versus the combination of placebo and Acetylcholinesterase (ACE) inhibitor medication ) over a period of six months to four years. The results showed that a dosage of 2,000 IU/d $\alpha$-tocopherol significantly delayed the progression of $\mathrm{AD}$ symptoms in mild to moderate $\mathrm{AD}$ and decreased caregiver burden. Moreover, the authors found no safety concern associated with vitamin E supplementation compared to the control group [46].

There are several ideas to explain the inconsistent results on the effect of vitamin E supplementation. According to Brewer's hypothesis, the antioxidant vitamin $\mathrm{E}$ is ineffective because the oxidized vitamin $\mathrm{E}$ is not removed from the membranes and is not reduced by vitamin $\mathrm{C}$ or any other antioxidant. Therefore it will either accumulate or pass the electron to another lipid, further damaging the membrane [47]. However, there is another possibility. Generally, $\alpha$-tocopherol is used as a supplement in clinical trials, but $\gamma$-tocopherol was found more effective in scavenging free radicals and nitrogen oxygen species that cause inflammation. Moreover, $\alpha$-tocopherol supplements significantly 
reduces serum $\gamma$-tocopherol concentration and this may have important biological effects. Therefore, $\alpha$-tocopherol may eliminate the favourable effects of other forms of vitamin $E$ in MCI and AD $[48,49]$.

Recently it was discussed in a comprehensive review that the difficulty in performing precise and uniform human studies is mostly responsible for the inconsistent outcomes reported in the literature. Therefore more standardized clinical research is needed to identify a clear effect of vitamin $E$ on cognitive decline observed during aging and $\mathrm{AD}$ progression from early to late phase [50].

Nutrition epidemiologic studies indicate that vitamin E from food sources may be more effective at preventing age related neurodegenerative disorders than dietary supplements. This could be partly explained by the fact that vitamin E from foods comprises all four tocopherols and four tocotrienols with different properties. Besides this, the combination of nutrients from food may have synergic effects [48, 49].

II. Vitamin C: The beneficial effect of high vitamin C intake on $\mathrm{AD}$ and MCI has grade I. evidence [35].

Vitamin C (ascorbic acid, the y-lactone of hexonic acid) is a water soluble vitamin. It is a very unstable compound and readily undergoes oxidation to dehydroascorbic acid. Vitamin $\mathrm{C}$ has a huge redox potential. It is a potent antioxidant and essential cofactor in numerous enzymatic reactions, e.g. in the biosynthesis of collagen, carnitine and catecholamine and is involved in the metabolism of cholesterol. It also increases the intestinal absorption of non-hem iron.

Sodium dependent adsorption of vitamin C is limited, $100 \%$ adsorption is observed at dose of $200 \mathrm{mg}$. When plasma vitamin C level reaches saturation, additional vitamin $\mathrm{C}$ is largely excreted into urine [51].

The effect of vitamin $C$ was investigated on $A \beta$ formation and behaviour in an AD mice model. Due to the effect of vitamin $C$, the reduction of $A \beta$ oligomerization was accompanied by marked decrease in brain oxidative damage and in the ratio of soluble $A \beta 42$ to $A \beta 40$, a typical indicator of $A D$ progression. Moreover, vitamin $C$ attenuated the phosphorylation of tau, but brain plaque deposition was not altered [52].

It has been shown, that as compared to control subjects, plasma vitamin $\mathrm{C}$ concentration is lower in $\mathrm{AD}$ patients and is negatively associated with the degree of cognitive impairment. This correlation seems to be independent of age, gender, Body Mass Index (BMI), diet, and vitamin $\mathrm{C}$ intake. AD subjects have increased lipid peroxidation levels and free radicals may cause damage in the neural tissue $[53,54]$.

However, the literature implicating vitamin $\mathrm{C}$ and other antioxidants in the promotion of cognitive function and the prevention of $\mathrm{AD}$ are conflicting. The relationship between $\mathrm{AD}$ and intake of vitamin $\mathrm{C}$ and/or $\mathrm{E}$ was investigated in elderly, who were free of dementia at baseline, and were followed on average for three years. The intake of vitamin $\mathrm{C}$ and/or $\mathrm{E}$ was not associated with a decreased risk of dementia or AD [55]. The Rotterdam prospective study had the same conclusion, namely vitamin C intake was not associated with dementia risk [56]. Two of eight studies, providing data from well characterized cohorts and epidemiologic populations, suggested benefit of vitamin $\mathrm{C}$ intake [54]. On the contrary, results of another prospective study suggested that combined use of vitamin $C$ and $E$ for at least three years was associated with the reduction of $\mathrm{AD}$ prevalence and incidence [57]. Harrison`s comprehensive review on vitamin $C$ for prevention of age-related cognitive decline and AD concluded that there are several unsolved problems in the published study results. For example, the classification of participants according to vitamin C status is inaccurate, the use of vitamin C supplements is sometimes erroneously recorded, vitamin C levels in plasma are not always reported and the estimated daily intake in food diaries may not be accurately assessed. Overall, maintaining optimal levels of vitamin $\mathrm{C}$ may have a protective effect against age-related cognitive decline and development of AD [58].

The Team of Alzheimer Drug Discovery Foundation summarized the effect of vitamin $\mathrm{C}$ and $\mathrm{E}$ supplements on dementia and $\mathrm{AD}$ as follows: It remains unclear whether vitamin $\mathrm{C}$ and $\mathrm{E}$ supplementation alone and in combination prevent cognitive decline or dementia; maintaining healthy levels of vitamin $\mathrm{C}$ and $\mathrm{E}$ with the diet may be more beneficial than supplementation [59].

Few studies have measured vitamin $\mathrm{C}$ in the Cerebrospinal Fluid (CSF). Higher CSF to plasma vitamin $\mathrm{C}$ ratio at baseline was associated with a slower rate of cognitive decline at a one year follow up study. The strength of this relationship was modified by CSF albumin index, a marker of Blood-Brain-Barrier (BBB) integrity. The CSF albumin index attenuated the association of CSF-plasma ascorbic acid ratio with cognitive outcomes. It has been suggested that BBB dysfunction may lead to diffusion of vitamin $C$ from the Central Nervous System (CNS) and may impair the brain`s ability to maintain the high CSF-plasma ratio in $\mathrm{AD}$ [60].

Epidemiological studies confirmed the relevance of the relationship between vascular disease and AD. Polidori et al. investigated the connection between the level of several antioxidants and Carotid Intima-Media-Thickness (C-IMT), as an indirect index of vascular damage. They established that higher vitamin $\mathrm{C}$ plasma levels appears to be protective against elevated C-IMT values in elderly. In the light of increased risk of cardiovascular disease, cerebrovascular disease and cognitive impairment shown in patients with increased C-IMT, the achievement of better antioxidant status in general and vitamin $\mathrm{C}$ in particular should be always encouraged in the elderly [61].

III. Folate: Folate is a generic term, referring to both natural folates (pteroyl glutamate) in the food and folic acid (pteroyll-glutamic acid), the synthetic form used in supplements and fortified food. Folate is a coenzyme and its principal role is to accept or donate one-carbon units. Vitamin B2 (riboflavin), vitamin B6 (pyridoxine) and vitamin B12 (cyanocobalamin) are required for the folate metabolism to serve one-carbon units [62, 63]. 
One of the key enzymes in the folate metabolism is 5,10-Methylene Tetrahydro Folate Reductase (MTHFR) that catalyzes the reduction of 5,10-methylenetetrahydrofolate to 5-methylenetetrahydrofolate, the methyl donor for methionine synthesis from homocysteine [62].

MTHFR is a rate-limiting enzyme in the methyl cycle, and it is encoded by the MTHFR gene. The MTHFR nucleotide at position 677 in the gene has two variants: $\mathrm{C}$ (cysteine) or $\mathrm{T}$ (thymine). $\mathrm{C}$ at position 677 is the normal allele, the $677 \mathrm{~T}$ allele encodes a thermolabile enzyme with reduced activity. Homozygous individuals with two copies of $677 \mathrm{C}$ (677C/C) have the most frequent genotype, while people with the $677 \mathrm{~T} / \mathrm{T}$ variant have lower MTHFR activity than $\mathrm{C} / \mathrm{T}$ or $\mathrm{C} / \mathrm{C}$ individuals. Thus homozygous 677T/T persons have higher Homocysteine (Hct) concentrations, and Hct shows negative (grade I.) association with $\mathrm{AD}$ as shown below [35].

Depending on the population, $20-53 \%$ of individuals may have inherited one $\mathrm{T}$ copy (677C/T genotype) and $3-32 \%$ of the individuals may have inherited two $\mathrm{T}$ copies $(677 \mathrm{~T} / \mathrm{T})$ for the MTHFR gene, compared to individuals with the most frequent $677 \mathrm{C} / \mathrm{C}$ homozygous genotype [64, 65].

There are numerous studies investigating the association between MTHFR genotypes, folate, vitamin B6, B12 intake and serum levels and Hct concentrations in connection with AD. Religa et al. found that the concentration of plasma total Hct is increased in $\mathrm{AD}$ patients and this may be associated with $\mathrm{T} / \mathrm{T}$ genotype in the MTHFR gene [66]. Recently, a comprehensive meta-analysis was performed involving in total 68 studies. Hct, folic acid and vitamin B12 levels in AD patients in comparison with controls, and their association with the risk of AD were evaluated. According to the results, AD patients may have lower levels of folate and vitamin B12 and higher level of Hct in plasma than controls. An age-subgroup analysis showed no age effect for Hct levels in plasma between AD patients and matched controls, while the differences in folate and vitamin B12 levels further expanded with increasing age. Data also suggested that high Hct and low folate levels may correlate with increased risk of $\mathrm{AD}$ occurrence [67].

Another comprehensive review and meta-analysis examined the role of vitamin B supplementation on MCI and AD. Results showed moderate beneficial effects of vitamin B supplementation on memory, whereas no significant difference on general cognitive function, executive function and attention were found in $\mathrm{MCI}$ patients. No significant cognitive benefits on the AD Assessment Scale and Mini Mental State Examination, functional, behavioural or global change were observed in AD patients. Collectively weak evidence of benefits were observed for the domains of memory in patients with MCI. Recent data does not yet provide adequate evidence of an effect of vitamin B on general cognitive function, executive function and attention in people with MCI. Similarly, folic acid alone or vitamin B in combination were unable to stabilize or slow down decline in cognition, function, behaviour and global change of AD patients [68].

A third meta-analysis investigated the effects of Hct lowering effect of B vitamin treatment on cognitive function and on the rate of cognitive age. According to the results, B vitamins lowered Hct concentrations, but had no significant effect on individual cognitive domains or global cognitive function or cognitive ageing [69].

IV. Vitamin D: Vitamin D is a fat-soluble seco-steroid hormone. It exists in two isomorphs: Vitamin D3 (cholecalciferol) is synthesized in the skin, and vitamin D2 (ergocalciferol) photosynthesized in plants. These inactive precursors are metabolized in the liver and kidneys. Following synthesis in the epidermis or dietary intake, both forms enter the circulation and are transported to the liver by the vitamin $\mathrm{D}$ binding protein. In the hepatocytes the inactive form is converted to 25-Hydroxyvitamin D3 or D2 (25(OH)D) which is activated in the kidney. The metabolically active form, 1,25-Dihidroxy Vitamin D $(1,25(\mathrm{OH} 2) \mathrm{D})$ is binding to Vitamin D Receptor (VDR) and directly or indirectly regulate hundreds of genes.

The major circulating form of vitamin $\mathrm{D}$ is the sum of 25(OH)D3 and 25(OH)D2 and used as a biomarker of vitamin D nutritional status [70]. VDRs are present in all the brain regions that are essential for cognition. Annweiler summarised the potential roles of vitamin D mediated by VDRs in the central nervous system as follows: Clearance of $\mathrm{A} \beta$ peptide; regulation of the intraneuronal calcium; anti-inflammatory action; antioxidative action; primary prevention and reduction of ischemic zone size; regulation of cholinacetyltransferase; regulation of neuro trophic agents [71].

a. Observational studies: Epidemiologic studies indicated that people with $\mathrm{AD}$ have lower vitamin $\mathrm{D}$ status than controls. A meta-analysis on the 25(OH)D status involving six studies proved that AD patients had lower levels of 25(OH)D than aged matched controls [71, 72]. Cross sectional and case control studies confirmed also that vitamin D concentrations are lower in individuals with cognitive impairment and dementia [73]. Recently published meta-analyses indicated that lower vitamin D status may be associated with an increased risk of developing dementia and AD [74].

b. Supplementation studies: Annweiler et al. studied the effect of vitamin D or memantine alone or combined in 43 outpatients (mean age $84.7 \pm 6.3$ years; $65.1 \%$ women) with new diagnosis of AD. Patients who took memantine plus vitamin D for six months had statistically and clinically increased cognitive improvement, meanwhile vitamin D or memantine alone showed no effect [75]. These results suggest that vitamin D supplementation is not sufficient to prevent AD by itself and so the development of a multi-target drug is necessary, using vitamin D supplements as an adjunct to standard anti-dementia treatments [71]. Based on the available data, the Vitamin D Council also concluded that other treatment should not be replaced by vitamin $\mathrm{D}$ in $\mathrm{AD}$ patients [76].

\section{New theories for the development of AD}

Vitamin D hypothesis: In early 2014, Gezen-Aket et al. presumed that long-term-hypovitaminosis D or inefficient 
utilizationofvitaminDmaybeaprimeinducer of neurodegeneration in ageing and $\mathrm{AD}$, which results in a long term hormonal imbalance. They hypothesized that vitamin $D$ has protective effects in the central nervous system, because it is involved in the regulation of neurotrophic factor production, neurotransmitter levels, oxidative stress metabolism, calcium homeostasis, immune system function and induction of $A \beta$ clearance. The term of insufficient utilization of vitamin $\mathrm{D}$ was suggested. According to the theory, vitamin $\mathrm{D}$ deficiency/hypovitaminosis has the potential result of accumulation of $A \beta$. On the other hand, $A \beta$ may disrupt the utilization of vitamin $D$ even if the systemic level of vitamin $D$ is sufficient. Due to the accumulation of $A \beta$, the number of VDRs decrease and 24-hydroxylase concentration increase. This may result in the alteration of vitamin $\mathrm{D}$ related genes and the consequence may be the inefficient utilization of vitamin $\mathrm{D}$ [77].

The role of arginine: Kan et al. studied the immune system of the CVN-AD mouse, a model of human AD. In the brain of the mouse model plaques, tangles and hippocampal neuron death are present, resulting in rodent memory loss. Areas of hippocampal neuron death were associated with the immunosuppressive CD11c+ microglia and extracellular arginase, resulting in arginine catabolism and reduced level of total brain arginine. Diflouromethyl-Ornitine (DFMO) was used to block arginase before the symptoms of $\mathrm{AD}$ appeared. As a result, fewer plaques could be identified and the mice performed better on memory tests. This study suggests that in AD certain immune cells that normally protect brain begin to abnormally consume arginine. The data indicate that immune suppression and arginine catabolism lead to a loss of arginine and its depravation is followed by cell death. Authors concluded, that in contrast to previous views which considered $\mathrm{AD}$ as driven by immunity and inflammation, it is rather associated with an immunosuppressive pattern [78].

The study of Kan et al. has been commented by several experts [79]: Spiers-Jones highlighted that the results need to be confirmed in other models as well before moving into human studies. According to Picket, the next step would be to show that targeting arginine metabolism in the brain can reduce the death of brain cells. Phipps warned that clinical trials are essential before any potential new treatment can be given to people. The question arised, whether arginine supplementation can prevent AD. Arginine supplementation is not recommended, because the blood-brain barrier would preventarginine to go into the brain, and even if it does get through, arginine would be still degraded by the arginase enzyme [80].

The best way to maintain a healthy brain throughout the life is to ensure a balanced diet, no smoking, being mentally and physically active with regular exercise, and to keep blood pressure and cholesterol level controlled, as summarised by Phipps.

It is undeniable that the hypothesis of Kan generated a new idea in Alzheimer research, but it needs more data to prove it [79].
The role of Polyunsaturated Fatty Acids (PUFAs): More than half of the solid brain matter is composed of membrane lipids, which are predominantly phospholipids. A large proportion of phospholipids are PUFAs, that belong to the $\omega-6$ and $\omega-3$ classes. AA, (arachidonic acid C20:4,n-6) and DHA, (docosahexaenoic acid C22:6,n-3) are the main components of these classes.

Eonic EPA (eicosapentaeonic acid C20:5,n-3) quickly disappears from the system.

The effects of PUFAs on the brain functions are the following: They modify neuronal membrane fluidity, membrane activity, the number and affinity of receptors, the function of neuronal membrane ionic channels, and the production of neurotransmitters and brain peptides.

Free $\omega-6$ and $\omega-3$ PUFAs are precursors to the local hormones, i.e. eicosanoids. Eicosanoids are involved in numerous brain functions, sometimes with conflicting or opposing effects. For example prostaglandins derived from $\omega-6$ PUFAs are highly potent and proinflammatory, but $\omega-3$ products have an antiinflammatory effect. Eicosanoids exert important effects on vascularity, including increased blood flow and permeability of various membranes. In the aging brain the concentration of $\omega-6$ PUFAs decrease, while $\omega-3$ PUFAs increase. It is suggested that the optimal ratio of $\omega-6 / \omega-3$ is $4: 1$ in the brain to protect and stabilize the neuronal membrane in health and disease [81, 82].

Several studies examined the effect of $\omega$-3 PUFAs on cognition and AD. In AD animal model, DHA has been demonstrated to reduce $A \beta$ production and pathological changes. However, the results in human studies are contradictory. Some studies suggest that supplementation or higher dietary intake of $\omega-3$ fatty acids are related to reduced risk of dementia and $A D$, while other studies failed to find this association [5, 41, 83-85]. In a study the connection among serum Hcy, $\omega-3$ fatty acids and B vitamins (folic acid, vitamins B6 and B12) was investigated. Participants with MCI with low $\omega-3$ status at the baseline showed no effect from B vitamin treatment, while those in highest tertile for $\omega-3$ fatty acid or DHA, B vitamins significantly slowed the rate of cognitive and clinical decline. Results call the attention to the necessity to investigate the interactions of different nutrients $[86,87]$. Recently, a meta-analysis was conducted to review the association of dietary intake of $\omega-3$ PUFAs or fish, an important source of $\omega-3$ fatty acids, and the incidence of dementia and AD. According to the results, dietary intake of $\omega$-3 PUFAs was not associated with lower risk of dementia or AD in any case.

Higher intake of fish did not have a significant association with lower risk of dementia, but a borderline significant $36 \%$ lower risk of $\mathrm{AD}$ was demonstrated for those with the highest fish intake. A dose-response meta-analysis showed that each $100 \mathrm{~g} /$ week intake of fish was associated with an 11\% lower risk of AD. The protective effect of fish intake may have several reasons: Fish is a good source of $\omega-3$ PUFAs, especially DHA. Fish is also a good source of other nutrients such as vitamins, essential amino acids and trace elements, and these may also contribute 
to cognitive function improvement. Generally, fish intake maybe associated with a healthier dietary pattern, and high fish intake maybe associated with lower intake of other types of fat, such as saturated fat. This meta-analysis also showed that the higher intake of fish was associated with lower risk of $A D$, while $\omega-3$ PUFAs intake did not influence the risk of dementia and AD [88].

The role of diabetes: Some papers suggest a connection between Type 2 Diabetes Mellitus (T2DM) and dementia and AD [89-91]. However, the findings are inconsistent. Some studies state that there is no direct relationship between $\mathrm{AD}$ and diabetes. It seems that diabetes is more strongly and consistently associated with vascular form of cognitive impairment rather than with AD like neurodegenerative forms [92, 93].

A recently issued meta-analysis showed no evidence based association between T2DM and AD in western population, however there is a significant association between T2DM and AD in Asian population [35].

To absolve this inconsistency, a concept has been proposed that $\mathrm{AD}$ might represent a specific form of brain diabetes and so de La Monte and Wands put forward the term 'type 3 diabetes' that selectively involves the brain. They proved with human and experimental animal studies that CNS impairments in Insulin/ Insulin Like Growth Factor (IGF) signalling mechanism can occur in the absence of Type 1 And 2 Diabetes Mellitus (T1DM and T2DM2). T2DM was not sufficient to cause AD, although it could be possible serve as a cofactor in its pathogenesis or progression. They concluded that $\mathrm{AD}$ is a neuro endocrine disease caused by selective impairments in insulin and IGF signalling mechanism, including deficiencies in local insulin and IGF production. The accompanying inflammatory response, oxidative stress, DNA damage and mitochondrial dysfunction have also been proposed to contribute to the degenerative cascade causing brain damage [94].

Obesity: A recent meta-analysis estimated grade I. evidence for high BMI in midlife as well as low BMI to be correlated with AD [35]. However, the available evidence from epidemiological studies associated with overweight and obesity as measured by BMI in midlife is still conflicting. The relationship between BMI in midlife and late-life and dementia was investigated in another meta-analysis. According to the follow-up prospective study in midlife, Underweight, overweight and obese BMIs were associated with increased risk of dementia as compared to the normal BMI. Risks appeared to be the highest for underweight and obese BMI. An U-shaped relationship was suggested between midlife BMI and late-life risk of dementia. Findings were similar for $\mathrm{AD}$ as well. But in late-life continuous BMI was not associated with dementia, probably because of some methodological factors, such as the insufficient length of follow-up and the small size of the groups [95].

According to a prospective population-based cohort with a 26 years follow-up study, higher midlife (mean age: $50.2 \pm 6.0$ y) BMI was related to higher risk of dementia and AD. Steeper decrease of BMI and low late-life (mean age: $71.2 \pm 4.9$ y) BMI were associated with higher risk of dementia and AD [96].
Luchsinger et al. compared the predictive value of BMI to dementia. Hazard ratios relating quartiles of BMI to dementia in persons $<76$ years old and persons $\geq 76$ years old were characterized. In persons $<76$ years old the association between BMI and dementia resembled an U-shape, the second and third quartiles were related to lower risk, while the fourth was similar to the reference. In older people, the risk of dementia decreased with increasing BMI. Continuing this study authors explored whether measures of central obesity were better predictors of AD compared to BMI in elderly. They established that the association between adiposity and dementia differs depending on anthropometric measures used and is modified by age. It has been shown that BMI loses predictive ability in the elderly and Waist To Hip Ratio (WHR) is a better predictor of AD compared to other measures. It also helps to explain the apparent discrepancies in studies reporting on obesity in elderly and $\operatorname{AD}[97,98]$.

The effects of some modifiable risk factors for $\mathrm{AD}$ and dementia are highlighted in Table 2.

\section{Dietary patterns and guidelines}

Diet and nutrition might be important modifiable risk factors of AD. Single nutrients are not consumed in isolation but as part of a diet. Examining the role of a single nutrient is difficult also due to the interaction between the different nutrients. Therefore examining foods, rather than single nutrients might be more useful [41]. Recently dietary pattern analysis was introduced, as a way for examining diet-disease relations in AD. Dietary pattern is defined as quantities, proportions, variety or combination of different foods, drinks and nutrients in diets and frequency, with which they are habitually consumed [99]. Among dietary patterns, Mediterranean, Japanese and healthy diets have been reported to be associated with lower risk of AD. However, further studies are needed to explore the importance of diets in dementia and AD [41].

A subgroup of the Dietary Guidelines Advisory Committee (DGACS2) assessed the connection between several dietary patterns, food and nutrients and dementia and AD. They concluded that patterns higher in fruits, vegetables, nuts, legumes and seafood were generally associated with reduced risk; patterns higher in red and/or processed meats were generally associated with greater risk; relatively few studies reported on refined sugar and added salt, but patterns including these nutrients tended to report greater risk [99].

At the International Conference on Nutrition and Brain, experts recommended guidelines for $\mathrm{AD}$ prevention as follows [100]:

1.) Minimize saturated trans-fat intake

2.) Vegetables, fruits, legumes and whole grains should replace meat and dairy products

3.) Vitamins should come from food, however, recommended intake and adequate status is difficult to achieve

4.) A reliable source of vitamin B12 providing at least the recommended daily allowance 


\begin{tabular}{|c|c|c|c|c|c|}
\hline Reference & Study selection & Purpose & $\begin{array}{l}\text { Number of studies } \\
\text { included, sample size }\end{array}$ & Main outcome & Conclusion \\
\hline $\begin{array}{l}\text { Farina et al. } 2012 \\
\text { [42] }\end{array}$ & $\begin{array}{l}\text { Double-blind } \\
\text { randomized trials }\end{array}$ & $\begin{array}{l}\text { To assess the efiicacy } \\
\text { of Vitamin E in the } \\
\text { treatment of AD } \\
\text { and prevention of } \\
\text { progression of MCI to } \\
\text { dementia }\end{array}$ & $\begin{array}{l}\text { Two studies analyzed } \\
\text { in } \mathrm{AD} \text { and one in } \mathrm{MCI} \\
\text { population }\end{array}$ & $\begin{array}{l}\text { First of the AD studies: } \\
\text { reported some benefit } \\
\text { from Vitamin E (Sano); } \\
\text { Second AD treatment } \\
\text { study: patients whose } \\
\text { oxidative stress markers } \\
\text { were lowered by Vitamin } \\
\text { E showed no improvement } \\
\text { in cognitive status (Lloyd); } \\
\text { Third study: Vitamin E } \\
\text { had no beneficial effect on } \\
\text { progression from MCI to AD. }\end{array}$ & $\begin{array}{l}\text { No convincig evidence } \\
\text { that Vitamin E treatment } \\
\text { is beneficial in the } \\
\text { treatment of AD or MCI. } \\
\text { In some cases increased } \\
\text { mortality. Vitamin E } \\
\text { should not be used for } \\
\text { the treatment of MCI } \\
\text { and AD. More trials are } \\
\text { needed and these should } \\
\text { include different forms } \\
\text { of Vitamin E. }\end{array}$ \\
\hline $\begin{array}{l}\text { ADDF } 2014 \text { [59], Li } \\
\text { et al. } 2012 \text { [103] }\end{array}$ & $\mathrm{n} / \mathrm{a}$ & $\begin{array}{l}\text { Evaluate the association } \\
\text { between dietary intake } \\
\text { of Vitamin } C, E, \beta \\
\text { Carotine and risk of AD }\end{array}$ & $\mathrm{n} / \mathrm{a}$ & $\begin{array}{l}\text { Dietary intake of these } \\
\text { antioxidants can lower } \\
\text { the risk of AD. Vitamin } \\
\text { E exhibiting the most } \\
\text { pronounced protective } \\
\text { effects. }\end{array}$ & $\begin{array}{l}\text { Findings will be of } \\
\text { significance in the } \\
\text { prevention and } \\
\text { interventional treatment } \\
\text { of AD. }\end{array}$ \\
\hline Shen \& Ji 2015 [67] & $\begin{array}{l}\text { Comprehensive } \\
\text { meta-analysis }\end{array}$ & $\begin{array}{l}\text { To evaluate: 1) Hcy, folic } \\
\text { acid and Vitamin B12 } \\
\text { levels in AD patients; } 2 \text { ) } \\
\text { the association between } \\
\text { Hcy, folic acid and B12 } \\
\text { levels and risk of AD }\end{array}$ & 68 & $\begin{array}{l}\text { 1) AD patients may } \\
\text { have higher level of } \\
\text { Hcy and lower levels of } \\
\text { folate and Vitamin B12. } \\
\text { 2) No age effect for Hcy } \\
\text { level in plasma. }\end{array}$ & $\begin{array}{l}\text { Analyses } 1 \text { ) confirmed } \\
\text { higher Hcy, lower folic } \\
\text { acid and B12 levels are } \\
\text { in AD patients; } 2 \text { ) Data } \\
\text { suggests that high Hcy } \\
\text { and low folic acid levels } \\
\text { my be risk factors of AD. }\end{array}$ \\
\hline Li et al. 2014 [68] & $\mathrm{n} / \mathrm{a}$ & $\begin{array}{l}\text { To assess the efficasy } \\
\text { of Vitamins B } \\
\text { supplementation in } \\
\text { slowing the rate of } \\
\text { cognitive, behavioral, } \\
\text { functional and global } \\
\text { decline in MCI and AD } \\
\text { patients }\end{array}$ & 5 trials were analized & $\begin{array}{l}\text { 1) Moderate beneficial } \\
\text { effects of Vitamins B } \\
\text { supplementation in } \\
\text { memory, no significant } \\
\text { difference in cognitive } \\
\text { and executive functions, } \\
\text { and attention in MCI } \\
\text { 2) No significant benefits on } \\
\text { cognitive functions in AD. }\end{array}$ & $\begin{array}{l}\text { Data does not provide } \\
\text { adequate evidence of an } \\
\text { effect of Vitamins B on } \\
\text { general cognitive and } \\
\text { executive functions and } \\
\text { attention in people with } \\
\text { MCI. Folic acid alone or } \\
\text { Vitamins B alone or in } \\
\text { combination are unable } \\
\text { to stabilize or slow } \\
\text { decline in cognition, } \\
\text { function, behaviour and } \\
\text { global change in AD. }\end{array}$ \\
\hline $\begin{array}{l}\text { Clarke et al. } 2014 \\
\text { [69] }\end{array}$ & $\begin{array}{l}\text { Placebo-controlled } \\
\text { randomized trials }\end{array}$ & $\begin{array}{l}\text { To assess the effects of } \\
\text { treatment with Vitamins } \\
\text { B administered for } \\
\text { several years, compared } \\
\text { to placebo on composite } \\
\text { domains of cognitive } \\
\text { functions, global } \\
\text { cognitive functions and } \\
\text { cognitive aging }\end{array}$ & $\begin{array}{l}11 \text { large randomized } \\
\text { trials in } 22,000 \text { patients. } \\
\text { Domain-based } Z \text { scores } \\
\text { (memory, speed and } \\
\text { executive function) before } \\
\text { and after treatment (mean } \\
\sim 2.3 y \text { ) in the } 4 \text { cognitive } \\
\text { domain trials ( } n=1,340 \text { ) } \\
\text { MMSE-Type tests at the } \\
\text { end of treatment (mean } \\
\sim 5 y \text { ) in } 7 \text { global cognition } \\
\text { trials ( } n=20,431 \text { ) }\end{array}$ & $\begin{array}{l}\text { Domain-composite } \\
\text { and MMSE-type global } \\
\text { cognitive function Z scores } \\
\text { decreased with age. B } \\
\text { vitamins lowered Hct in } \\
\text { cognitive-domain trials, } \\
\text { but no significant effects } \\
\text { on the Z scores differences } \\
\text { from baseline for individual } \\
\text { domains or for global } \\
\text { cognitive function - similar } \\
\text { effect in the global cognition } \\
\text { trials. }\end{array}$ & $\begin{array}{l}\text { Hcy lowering with B } \\
\text { vitamins has no effect } \\
\text { on individual cognitive } \\
\text { domains or global } \\
\text { cognitive functions nor } \\
\text { cognitive aging. }\end{array}$ \\
\hline $\begin{array}{l}\text { Zhao et al. } 2013 \\
{[72]}\end{array}$ & $\mathrm{n} / \mathrm{a}$ & $\begin{array}{l}\text { To examine the } 25(\mathrm{OH}) \\
\text { D status in AD patients }\end{array}$ & $\begin{array}{l}6 \text { studies, } 319 \text { patients and } \\
573 \text { controls }\end{array}$ & $\begin{array}{l}\text { AD patients had lower } \\
\text { levels of } 25(\mathrm{OH}) \mathrm{D} \text { levels } \\
\text { than controls }\end{array}$ & $\begin{array}{l}\text { Despite the similar } \\
\text { mean age of AD patients } \\
\text { and controls, patients } \\
\text { had lower levels of } \\
\text { 25(OH)D than controls. }\end{array}$ \\
\hline
\end{tabular}




\begin{tabular}{|c|c|c|c|c|c|}
\hline Shen \& Ji 2015 [74] & $\begin{array}{l}\text { Random-effect } \\
\text { model }\end{array}$ & $\begin{array}{l}\text { To estimate the } \\
\text { assiciation between } \\
\text { vitamin D deficiency } \\
\text { and risk of developing } \\
\text { AD and dementia }\end{array}$ & $\begin{array}{l}\text { Flowchart selection from } \\
526 \text { references, } 5 \text { studies } \\
\text { included }\end{array}$ & $\begin{array}{l}\text { Subjects with deficient } \\
\text { vitamin D status }(25(\mathrm{OH}) \\
\text { D<50nmol/l were at } \\
\text { increased risk of developing } \\
\text { AD and dementia. }\end{array}$ & $\begin{array}{l}\text { Data indicate that } \\
\text { vitamin D deficiency } \\
\text { maybe assiciated } \\
\text { with increased } \\
\text { risk of developing } \\
\text { AD and dementia. } \\
\text { Studies are needed to } \\
\text { evaluate the beneficial } \\
\text { effects of vitamin D } \\
\text { supplementation. }\end{array}$ \\
\hline WU et al. 2015 [88] & Prospective cohort & $\begin{array}{l}\text { To review the } \\
\text { association between } \\
\text { dietary intake of long- } \\
\text { chain } \mathrm{n}-3 \text { fatty acids } \\
\text { (FA), fish and the } \\
\text { incidence of dementia } \\
\text { and } \mathrm{AD}\end{array}$ & $\begin{array}{l}\text { 1,361 potentially relevant } \\
\text { articles; } 6 \text { studies included }\end{array}$ & $\begin{array}{l}\text { 1) Higher dietary intake } \\
\text { of n-3 FAs was not } \\
\text { associated with lower } \\
\text { risk of AD or dementia. } \\
\text { 2) Higher intake of fish was } \\
\text { associated with lower risk } \\
\text { of dementia. }\end{array}$ & $\begin{array}{l}\text { Most studies confirmed } \\
\text { an inverse relationship } \\
\text { between higher fish } \\
\text { intake and AD, but } \\
\text { statistically significant } \\
\text { association between } \\
\text { long chain n-3FA intake } \\
\text { and AD risk was not } \\
\text { evident. }\end{array}$ \\
\hline $\begin{array}{l}\text { Anstey et al. } 2011 \\
\text { [95] }\end{array}$ & Prospective cohort & $\begin{array}{l}\text { Evaluate the association } \\
\text { of BMI with risk of } \\
\text { dementia in midlife and } \\
\text { late life }\end{array}$ & 15 prospective studies & $\begin{array}{l}\text { Underweight, overweight } \\
\text { and obese individuals have } \\
\text { increased dementia risk. } \\
\text { Risks appeared to be the } \\
\text { highest for underweight } \\
\text { and obese BMI, suggesting } \\
\text { a U-shaped relationship } \\
\text { between midlife BMI and } \\
\text { dementia risk. Findings } \\
\text { were similar for AD and any } \\
\text { other dementia. }\end{array}$ & $\begin{array}{l}\text { Reducing the impact } \\
\text { of obesity on dementia } \\
\text { prevalence and } \\
\text { incidence should be } \\
\text { priority to governments, } \\
\text { health providers and the } \\
\text { general public. }\end{array}$ \\
\hline
\end{tabular}

5.) If using multivitamins, choose those without iron, copper

6.) Although aluminium's role in $\mathrm{AD}$ remains a matter of investigations those who desire to minimize their exposure can avoid to use products that contain aluminium

7.) Include aerobe exercise in your routine

\section{Conclusion}

Considering that the incidence and prevalence of currently incurable $\mathrm{AD}$ is constantly and rapidly increasing in the ageing societies worldwide, besides pharmaceutical drug development there is an urgent need for alternative solutions for both prevention and treatment. Optimizing the nutritional status of the general population as a preventive measure may provide additional support to therapeutic concepts as they become available [5]. However, currently the scientific evidence regarding the effects of diet and nutrients on AD is incomplete and there are still a lot of opportunities for the nutrition scientists to contribute to the clarification of the conflicting results and adjust guidelines accordingly [100, 101]. Nevertheless, pathophysiological characteristics of $\mathrm{AD}$ such as neuroinflammation, glucose dysregulation, homocysteine accumulation and neuronal loss can be considerably and positively influenced by proper nutrition [102]. Moreover, already several RCTs have demonstrated promising results for nutrients to decrease the risk of developing $\mathrm{AD}$ and maintaining cognitive performance. Thus, lifelong optimal supply of essential micro- and macronutrients may greatly contribute to delay the onset of AD.

\section{Conflict of Interest}

MA received an honorarium from DSM Nutritional Products Ltd. for writing the article. SP and ME are employees of DSM Nutritional Products Ltd.

\section{References}

1. WHO. Global Health Observatory (GHO) Data. 2015 [cited 2016 July 8]; Available from: http://www.who.int/gho/mortality_burden_disease/ life_tables/en/.

2. Organization WH. World health statistics 2016: monitoring health for the SDGs, sustainable development goals. Geneva: World Health Organization, 2016.

3. Eurostat. Population structure and aging. 2015 [cited 2016 July 11]; Available from: http://ec.europa.eu/eurostat/statistics-explained/ index.php/Population_structure_and_ageing.

4. Kinsella K, He W. An Aging World: 2008. Washington, DC: U.S. Census Bureau, 2009 Contract No.: P95/09-1.

5. Mohajeri MH, Troesch B, Weber P. Inadequate supply of vitamins and DHA in the elderly: implications for brain aging and Alzheimertype dementia. Nutrition. 2015;31(2):261-275. doi: 10.1016/j. nut.2014.06.016.

6. WHO. Dementia Fact sheet. 2016 [cited 2016 November 11]; Available from: http://www.who.int/mediacentre/factsheets/fs362/en/.

7. Alzheimer's A. Alzheimer's disease facts and figures. Alzheimers Dement. 2015;11(3):332-384.

8. Alzheimer A, Stelzmann RA, Schnitzlein HN, Murtagh FR. An English 
translation of Alzheimer's 1907 paper, “Uber eine eigenartige Erkankung der Hirnrinde”. Clin Anat. 1995;8(6):429-31. doi:10.1002/ ca. 980080612 .

9. Jiang T, Yu JT, Tian Y, Tan L. Epidemiology and etiology of Alzheimer's disease: from genetic to non-genetic factors. Current Alzheimer research. 2013;10(8):852-867.

10.Association As. Stages of Alzheimer's. 2016 [cited 2016 August 24]; Available from: http://www.alz.org/alzheimers_disease_stages_of_ alzheimers.asp.

11.Canada AS. Risk Factors. 2014 [cited 2016 July 11]; Available from http://www.alzheimer.ca/en/About-dementia/Alzheimer-s-disease/ Risk-factors.

12. Barron AM, Pike CJ. Sex hormones, aging, and Alzheimer's disease. Frontiers in bioscience. 2012;4:976-997.

13. Vest RS, Pike CJ. Gender, sex steroid hormones, and Alzheimer's disease. Hormones and behavior. $2013 ; 63(2): 301-307$. doi: 10.1016/j yhbeh.2012.04.006.

14. Ansar S. Alzheimerís Disease: Know The Risk Factors. IJHSR. 2014;4(4):180-187.

15. Agostinho P, Cunha RA, Oliveira C. Neuroinflammation, oxidative stress and the pathogenesis of Alzheimer's disease. Curr Pharm Des. 2010;16(25):2766-2778.

16. Reitz C. Alzheimer's disease and the amyloid cascade hypothesis: a critical review. Int J Alzheimers Dis. 2012;2012:369808.

17. Weggen S, Beher D. Molecular consequences of amyloid precursor protein and presenilin mutations causing autosomal-dominant Alzheimer's disease. Alzheimers Res Ther. 2012;4(2):9. doi: 10.1186/ alzrt107.

18. Bagyinszky E, Youn YC, An SS, Kim S. The genetics of Alzheimer's disease. Clin Interv Aging. 2014;9:535-551. doi: 10.2147/CIA.S51571.

19. Binder LI, Guillozet-Bongaarts AL, Garcia-Sierra F, Berry RW. Tau, tangles, and Alzheimer's disease. Biochim Biophys Acta. 2005;1739(23):216-223. doi: 10.1016/j.bbadis.

20. Musiek ES, Holtzman DM. Three dimensions of the amyloid hypothesis: time, space and 'wingmen'. Nat Neurosci. 2015;18(6):800-806.doi: 10.1038/nn.4018.

21. Herrup K. The case for rejecting the amyloid cascade hypothesis. Nat Neurosci. 2015;18(6):794-799. doi: 10.1038/nn.4017.

22. Morris GP, Clark IA, Vissel B. Inconsistencies and controversies surrounding the amyloid hypothesis of Alzheimer's disease. Acta Neuropathol Commun. 2014;2:135. doi: 10.1186/s40478-014-01355.

23. Tarasoff-Conway JM, Carare RO, Osorio RS, Glodzik L, Butler T, Fieremans E, et al. Clearance systems in the brain-implications for Alzheimer disease. Nat Rev Neurol. 2015;11(8):457-70. doi: 10.1038/ nrneurol.2015.119.

24. Evans DA, Funkenstein HH, Albert MS, Scherr PA, Cook NR, Chown MJ, et al. Prevalence of Alzheimer's disease in a community population of older persons. Higher than previously reported. JAMA. 1989;262(18):2551-2556.

25. Verghese PB, Castellano JM, Holtzman DM. Apolipoprotein E in Alzheimer's disease and other neurological disorders. Lancet Neurol. 2011;10(3):241-252. doi: 10.1016/S1474-4422(10)70325-2.

26. Liu CC, Kanekiyo T, Xu H, Bu G. Apolipoprotein Eand Alzheimer disease: risk, mechanisms and therapy. Nat Rev Neurol. 2013;9(2):106-118. doi: 10.1038/nrneurol.2012.263.
27. Huang Y. Roles of apolipoprotein E4 (ApoE4) in the pathogenesis of Alzheimer's disease: lessons from ApoE mouse models. Biochem Soc Trans. 2011;39(4):924-932. doi: 10.1042/BST0390924.

28. Farlow MR, He Y, Tekin S, Xu J, Lane R, Charles HC. Impact of APOE in mild cognitive impairment. Neurology. 2004 Nov 23;63(10):18981901.

29. Huang DY, Weisgraber KH, Goedert M, Saunders AM, Roses AD, Strittmatter WJ. ApoE3 binding to tau tandem repeat $I$ is abolished by tau serine262 phosphorylation. Neuroscience letters. 1995;192(3):209-212.do: 10.1016/0304-3940(95)11649-H.

30. International AsD. World Alzheimer Report 2014. London: Alzheimer's Disease International, 2014.

31. Perneczky R, Wagenpfeil S, Lunetta KL, Cupples LA, Green RC, Decarli C, et al. Head circumference, atrophy, and cognition: implications for brain reserve in Alzheimer disease. Neurology. 2010;75(2):137-142. doi: 10.1212/WNL.0b013e3181e7ca97.

32. Guo LH, Alexopoulos P, Wagenpfeil S, Kurz A, Perneczky R. Alzheimer's Disease Neuroimaging I. Brain size and the compensation of Alzheimer's disease symptoms: a longitudinal cohort study. Alzheimers Dement. 2013;9(5):580-586. doi: 10.1016/j.jalz.2012.10.002.

33. Tucker AM, Stern Y. Cognitive reserve in aging. Current Alzheimer research. 2011;8(4):354-360.

34. Stern Y. Cognitive reserve and Alzheimer disease. Alzheimer Dis Assoc Disord. 2006;20(2):112-7.

35. Xu W, Tan L, Wang HF, Jiang T, Tan MS, Tan L, et al. Meta-analysis of modifiable risk factors for Alzheimer's disease. J Neurol Neurosurg Psychiatry. 2015 Dec;86(12):1299-1306.

36. Higdon J. Vitamin E. Linus Pauling Institute Micronutrient Information Center; 2015 [cited 2016 July 11]; Available from: http://lpi. oregonstate.edu/mic/vitamins/vitamin-E.

37. Cardoso BR, Cominetti C, Cozzolino SM. Importance and management of micronutrient deficiencies in patients with Alzheimer's disease. Clin Interv Aging. 2013;8:531-542. doi: 10.2147/CIA.S27983.

38.Jiang Q. Natural forms of vitamin E: metabolism, antioxidant, and anti-inflammatory activities and their role in disease prevention and therapy. Free Radic Biol Med. 2014;72:76-90. doi: 10.1016/j. freeradbiomed.2014.03.035.

39. Ricciarelli R, Tasinato A, Clement S, Ozer NK, Boscoboinik D, Azzi A. alpha-Tocopherol specifically inactivates cellular protein kinase $C$ alpha by changing its phosphorylation state. Biochem J. 1998;334 ( Pt 1):243-249.

40.Zingg JM, Azzi A. Non-antioxidant activities of vitamin E. Curr Med Chem. 2004;11(9):1113-1133.

41. Hu N, Yu JT, Tan L, Wang YL, Sun L, Tan L. Nutrition and the risk of Alzheimer's disease. Biomed Res Int. 2013;2013:524820. doi: $10.1155 / 2013 / 524820$.

42. Farina N, Isaac MG, Clark AR, Rusted J, Tabet N. Vitamin E for Alzheimer's dementia and mild cognitive impairment. Cochrane Database Syst Rev. 2012;11:CD002854. doi: 10.1002/14651858. CD002854.

43. Sano M, Ernesto C, Thomas RG, Klauber MR, Schafer K, Grundman $\mathrm{M}$, et al. A controlled trial of selegiline, alpha-tocopherol, or both as treatment for Alzheimer's disease. The Alzheimer's Disease Cooperative Study. N Engl J Med. 1997;336(17):1216-1222. DOI: 10.1056/NEJM199704243361704. 
44. Lloret A, Badia MC, Mora NJ, Pallardo FV, Alonso MD, Vina J. Vitamin E paradox in Alzheimer's disease: it does not prevent loss of cognition and may even be detrimental. J Alzheimers Dis. 2009;17(1):143-149. doi: 10.3233/JAD-2009-1033.

45. Petersen RC, Thomas RG, Grundman M, Bennett D, Doody R, Ferris $\mathrm{S}$, et al. Vitamin $\mathrm{E}$ and donepezil for the treatment of mild cognitive impairment. N Engl J Med. 2005;352(23):2379-2388. DOI: 10.1056/ NEJMoa050151.

46. Dysken MW, Sano M, Asthana S, Vertrees JE, Pallaki M, Llorente $M$, et al. Effect of vitamin $E$ and memantine on functional decline in Alzheimer disease: the TEAM-AD VA cooperative randomized trial. JAMA. 2014;311(1):33-44. doi: 10.1001/jama.2013.282834.

47. Brewer GJ. Why vitamin E therapy fails for treatment of Alzheimer's disease. J Alzheimers Dis. 2010;19(1):27-30. doi: 10.3233/JAD-20101238.

48. Usoro OB, Mousa SA. Vitamin E forms in Alzheimer's disease: a review of controversial and clinical experiences. Crit Rev Food Sci Nutr. 2010;50(5):414-419. doi: 10.1080/10408390802304222.

49. Morris MC, Evans DA, Tangney CC, Bienias JL, Wilson RS, Aggarwal NT, et al. Relation of the tocopherol forms to incident Alzheimer disease and to cognitive change. Am J Clin Nutr. 2005 Feb;81(2):508-514.

50. La Fata G, Weber P, Mohajeri MH. Effects of vitamin E on cognitive performance during ageing and in Alzheimer's disease. Nutrients. 2014;6(12):5453-5472. doi: 10.3390/nu6125453.

51. Higdon J. Vitamin C. Linus Pauling Institute Micronutrient Information Center; 2013 [cited 2016 July 13]; Available from: http://lpi. oregonstate.edu/mic/vitamins/vitamin-C.

52. Murakami K, Murata N, Ozawa Y, Kinoshita N, Irie K, Shirasawa $\mathrm{T}$, et al. Vitamin $\mathrm{C}$ restores behavioral deficits and amyloid-beta oligomerization without affecting plaque formation in a mouse model of Alzheimer's disease. J Alzheimers Dis. 2011;26(1):7-18. doi: 10.3233/JAD-2011-101971.

53. Riviere S, Birlouez-Aragon I, Nourhashemi F, Vellas B. Low plasma vitamin C in Alzheimer patients despite an adequate diet. Int J Geriatr Psychiatry. 1998;13(11):749-754.

54. Bowman GL. Ascorbic acid, cognitive function, and Alzheimer's disease: a current review and future direction. BioFactors. 2012;38(2):114122. doi: $10.1002 /$ biof.1002.

55. Fillenbaum GG, Kuchibhatla MN, Hanlon JT, Artz MB, Pieper CF, Schmader KE, et al. Dementia and Alzheimer's disease in communitydwelling elders taking vitamin $C$ and/or vitamin E. Ann Pharmacother. 2005;39(12):2009-2014. DOI: 10.1345/aph.1G280.

56. Devore EE, Grodstein F, van Rooij FJ, Hofman A, Stampfer MJ, Witteman JC, et al. Dietary antioxidants and long-term risk of dementia. Arch Neurol. 2010;67(7):819-825. doi: 10.1001/archneurol.2010.144.

57.Zandi PP, Anthony JC, Khachaturian AS, Stone SV, Gustafson D, Tschanz JT, et al. Reduced risk of Alzheimer disease in users of antioxidant vitamin supplements: the Cache County Study. Arch Neurol. 2004;61(1):82-88. DOI: 10.1001/archneur.61.1.82.

58. Harrison FE. A critical review of vitamin C for the prevention of agerelated cognitive decline and Alzheimer's disease. J Alzheimers Dis. 2012;29(4):711-726. doi: 10.3233/JAD-2012-111853.

59.ADDF. Vitamin C and E Supplements. Alzheimer's Drug Discovery Foundation; 2014 [cited 2016 July 13]; Available from: http:// www.alzdiscovery.org/cognitive-vitality/report/vitamin-c-and-esupplements.
60. Bowman GL, Dodge H, Frei B, Calabrese C, Oken BS, Kaye JA, et al. Ascorbic acid and rates of cognitive decline in Alzheimer's disease. J Alzheimers Dis. 2009;16(1):93-98. doi: 10.3233/JAD-2009-0923.

61. Polidori MC, Ruggiero C, Croce MF, Raichi T, Mangialasche F, Cecchetti $\mathrm{R}$, et al. Association of increased carotid intima-media thickness and lower plasma levels of vitamin $\mathrm{C}$ and vitamin $\mathrm{E}$ in old age subjects: implications for Alzheimer's disease. J Neural Transm (Vienna). 2015;122(4):523-530. doi: 10.1007/s00702-014-1357-1.

62. Higdon J. Folate. Linus Pauling Institute Micronutrient Information Center; 2014 [cited 2016 July 13]; Available from: http://lpi. oregonstate.edu/mic/vitamins/folate.

63. Bailey LB, Gregory JF, 3rd. Folate metabolism and requirements. J Nutr. 1999;129(4):779-782.

64. Brattstrom L, Wilcken DE, Ohrvik J, Brudin L. Common methylenetetrahydrofolate reductase gene mutation leads to hyperhomocysteinemia but not to vascular disease: the result of a meta-analysis. Circulation. 1998;98(23):2520-2526.

65. BaileyLB,GregoryJF,3rd.Polymorphismsofmethylenetetrahydrofolate reductase and other enzymes: metabolic significance, risks and impact on folate requirement. J Nutr. 1999;129(5):919-22.

66. Religa D, Styczynska M, Peplonska B, Gabryelewicz T, Pfeffer A, Chodakowska M, et al. Homocysteine, apolipoproteine $\mathrm{E}$ and methylenetetrahydrofolate reductase in Alzheimer's disease and mild cognitive impairment. Dementia and geriatric cognitive disorders. 2003;16(2):64-70.

67. Shen L, Ji HF. Associations between Homocysteine, Folic Acid, Vitamin B12 and Alzheimer's Disease: Insights from Meta-Analyses. J Alzheimers Dis. 2015;46(3):777-790. doi: 10.3233/JAD-150140.

68. Li MM, Yu JT, Wang HF, Jiang T, Wang J, Meng XF, et al. Efficacy of vitamins $\mathrm{B}$ supplementation on mild cognitive impairment and Alzheimer's disease: a systematic review and meta-analysis. Current Alzheimer research. 2014;11(9):844-852.

69. Clarke R, Bennett D, Parish S, Lewington S, Skeaff M, Eussen SJ, et al. Effects of homocysteine lowering with $B$ vitamins on cognitive aging: meta-analysis of 11 trials with cognitive data on 22,000 individuals. Am J Clin Nutr. 2014;100(2):657-66. doi: 10.3945/ajcn.113.076349.

70. Higdon J. Vitamin D. Linus Pauling Institute Micronutrient Information Center; 2014 [cited 2016 July 13]; Available from: http://lpi. oregonstate.edu/mic/vitamins/vitamin-D.

71. Annweiler C, Karras SN, Anagnostis P, Beauchet O. Vitamin D supplements: a novel therapeutic approach for Alzheimer patients. Frontiers in pharmacology. 2014;5:6. doi: 10.3389/fphar.2014.00006.

72.Zhao Y, Sun Y, Ji HF, Shen L. Vitamin D levels in Alzheimer's and Parkinson's diseases: a meta-analysis. Nutrition. 2013;29(6):828-832. doi: 10.1016/j.nut.2012.11.018.

73. Littlejohns T, Kos K, Henley WE, Kuźma E, Llewellyn DJ. Vitamin D and Dementia. The Journal of Prevention of Alzheimer's Disease. 2015;3(1):43-52.

74. Shen L, Ji HF. Vitamin D deficiency is associated with increased risk of Alzheimer's disease and dementia: evidence from meta-analysis. Nutr J. 2015;14:76. doi: 10.1186/s12937-015-0063-7.

75. Annweiler C, Herrmann FR, Fantino B, Brugg B, Beauchet 0 . Effectiveness of the combination of memantine plus vitamin $D$ on cognition in patients with Alzheimer disease: a pre-post pilot study. Cognitive and behavioral neurology : official journal of the Society for Behavioral and Cognitive Neurology. 2012;25(3):121-127. doi: 10.1097/WNN.0b013e31826df647. 
76. Council VD. Alzheimer's disease. 2015 [cited 2016 July 13]; Available from: https://www.vitamindcouncil.org/health-conditions/alzheimers-disease/.

77. Gezen-Ak D, Yilmazer S, Dursun E. Why vitamin D in Alzheimer's disease? The hypothesis. J Alzheimers Dis. 2014;40(2):257-69. doi: 10.3233/JAD-131970.

78. Kan MJ, Lee JE, Wilson JG, Everhart AL, Brown CM, Hoofnagle AN, et al. Arginine deprivation and immune suppression in a mouse model of Alzheimer's disease. J Neurosci. 2015;35(15):5969-5982.

79. Centre SM. Expert reaction to arginine and Alzheimer's. 2015 [cited 2016 July 13]; Available from: http://www.sciencemediacentre.org/ expert-reaction-to-arginine-and-alzheimers/.

80. Today D. A New Potential Cause for Alzheimer's: Arginine Deprivation. 2015 [cited 2016 July 13]; Available from: https://today.duke. edu/2015/04/arginine.

81.Yehuda S. Omega-6/omega-3 ratio and brain-related functions. World review of nutrition and dietetics. 2003;92:37-56.

82.Velasco A, Tan, ZS. Fatty acids and the aging brain. In: Watson R, de Mesteer, editor. Omega-3 fatty acids in brain and neurological health: Elsevier; 2014.

83. Engelhart MJ, Geerlings MI, Ruitenberg A, Van Swieten JC, Hofman A, Witteman JC, et al. Diet and risk of dementia: Does fat matter?: The Rotterdam Study. Neurology. 2002;59(12):1915-1921.

84. Morris MC, Evans DA, Bienias JL, Tangney CC, Bennett DA, Wilson RS, et al. Consumption of fish and n-3 fatty acids and risk of incident Alzheimer disease. Arch Neurol. 2003;60(7):940-946. DOI: 10.1001/ archneur.60.7.940.

85. Schaefer EJ, Bongard V, Beiser AS, Lamon-Fava S, Robins SJ, Au R, et al. Plasma phosphatidylcholine docosahexaenoic acid content and risk of dementia and Alzheimer disease: the Framingham Heart Study. Arch Neurol. 2006;63(11):1545-1550. DOI: 10.1001/archneur.63.11.1545.

86. Jerneren F, Elshorbagy AK, Oulhaj A, Smith SM, Refsum H, Smith AD. Brain atrophy in cognitively impaired elderly: the importance of long-chain omega- 3 fatty acids and B vitamin status in a randomized controlled trial. Am J Clin Nutr. 2015;102(1):215-221. doi: 10.3945/ ajcn.114.103283.

87. Oulhaj A, Jerneren F, Refsum H, Smith AD, de Jager CA. Omega-3 Fatty Acid Status Enhances the Prevention of Cognitive Decline by B Vitamins in Mild Cognitive Impairment. J Alzheimers Dis. 2015;50(2):547-557. doi: 10.3233/JAD-150777.

88. Wu S, Ding Y, Wu F, Li R, Hou J, Mao P. Omega-3 fatty acids intake and risks of dementia and Alzheimer's disease: a meta-analysis. Neuroscience and biobehavioral reviews. 2015;48:1-9. doi: 10.1016/j. neubiorev.2014.11.008.

89. Whitmer RA. Type 2 diabetes and risk of cognitive impairment and dementia. Current neurology and neuroscience reports. 2007;7(5):373-380.

90.Xu WL, von Strauss E, Qiu CX, Winblad B, Fratiglioni L. Uncontrolled diabetes increases the risk of Alzheimer's disease: a population-based cohort study. Diabetologia. 2009;52(6):1031-1039. doi: 10.1007/ s00125-009-1323-x.

91. Yarchoan M, Arnold SE. Repurposing diabetes drugs for brain insulin resistance in Alzheimer disease. Diabetes. 2014;63(7):2253-2261. doi: $10.2337 / \mathrm{db} 14-0287$.

92. Hassing LB, Johansson B, Nilsson SE, Berg S, Pedersen NL, Gatz M, et al. Diabetes mellitus is a risk factor for vascular dementia, but not for Alzheimer's disease: a population-based study of the oldest old. International psychogeriatrics / IPA. 2002;14(3):239-248.

93. Kravitz E, Schmeidler J, Schnaider Beeri M. Type 2 diabetes and cognitive compromise: potential roles of diabetes-related therapies. Endocrinology and metabolism clinics of North America. 2013;42(3):489-501. DOI: 10.1016/j.ecl.2013.05.009.

94. de la Monte SM, Wands JR. Alzheimer's disease is type 3 diabetesevidence reviewed. Journal of diabetes science and technology. 2008;2(6):1101-1113.

95. Anstey KJ, Cherbuin N, Budge M, Young J. Body mass index in midlife and late-life as a risk factor for dementia: a meta-analysis of prospective studies. Obes Rev. 2011;12(5):e426-37. doi: 10.1111/j.1467-789X.2010.00825.x.

96. Tolppanen AM, Ngandu T, Kareholt I, Laatikainen T, Rusanen M, Soininen $\mathrm{H}$, et al. Midlife and late-life body mass index and late-life dementia: results from a prospective population-based cohort. J Alzheimers Dis. 2014;38(1):201-209. doi: 10.3233/JAD-130698.

97. Luchsinger JA, Patel B, Tang MX, Schupf N, Mayeux R. Measures of adiposity and dementia risk in elderly persons. Arch Neurol. 2007;64(3):392-398. DOI: 10.1001/archneur.64.3.392.

98. Luchsinger JA, Cheng D, Tang MX, Schupf N, Mayeux R. Central obesity in the elderly is related to late-onset Alzheimer disease. Alzheimer Dis Assoc Disord. 2012;26(2):101-105. doi: 10.1097/ WAD.0b013e318222f0d4.

99. Committee DGA. Scientific Report of the 2015 Dietary Guidelines Advisory Committee. 2015.

100. Barnard ND, Bush AI, Ceccarelli A, Cooper J, de Jager CA, Erickson $\mathrm{KI}$, et al. Dietary and lifestyle guidelines for the prevention of Alzheimer's disease. Neurobiol Aging. 2014;35 Suppl 2:S74-S78. doi: 10.1016/j.neurobiolaging.2014.03.033.

101. Lista S, Dubois B, Hampel H. Paths to Alzheimer's disease prevention: from modifiable risk factors to biomarker enrichment strategies. The journal of nutrition, health \& aging. 2015;19(2):154163. doi: $10.1007 / \mathrm{s} 12603-014-0515-3$.

102. Wilkinson D. Nutrition and Alzheimer's disease. GOED Exchange2016.

103. Li FJ, Shen L, Ji HF. Dietary intakes of vitamin E, vitamin C, and beta-carotene and risk of Alzheimer's disease: a meta-analysis. J Alzheimers Dis. 2012;31(2):253-258. doi: 10.3233/JAD-2012120349. 